\title{
Quality Improvement Guidelines for Transcatheter Embolization for Acute Gastrointestinal Nonvariceal Hemorrhage
}

\author{
Vlastimil Valek $\cdot$ Jakub Husty
}

Received: 25 January 2012/ Accepted: 5 July 2012/Published online: 13 November 2012

(C) Springer Science+Business Media, LLC and the Cardiovascular and Interventional Radiological Society of Europe (CIRSE) 2012

\section{Introduction}

Acute gastrointestinal (GI) bleeding is associated with significant morbidity and mortality [1]. Most cases are treated medically by correction of coagulation or endoscopically. Nonetheless, there remains a group of patients with significant bleeding for which these methods fail and endovascular treatment is indicated. Endovascular treatment is now the preferred option compared with open surgery due to the advantages of reduced morbidity and mortality.

Acute gastrointestinal bleeding is classically divided into two groups according to its relationship to the ligament of Treitz: upper and lower GI bleeding. Differentiating upper and lower GI bleeding based on the clinical presentation of enterorrhagia, melana, and hematemesis may be difficult and unreliable. Bleeding from the upper gastrointestinal tract is more frequent with incidence 1 per 1,000 persons [2], causing up to $70 \%$ of all gastrointestinal bleeding [1]. The most frequent etiology is bleeding from peptic ulcer disease and gastritis [3]. Less frequent causes are variceal bleeding in portal hypertension, Mallory-Weiss syndrome, and tumors [4]. Lower gastrointestinal bleeding causes approximately $30 \%$ of all gastrointestinal bleeding. The most frequent etiology is diverticulosis and less frequent is bleeding in angiodysplasia, tumors, inflammatory disease, and bleeding from Meckel's diverticulum [4, 5]. A separate group comprises hemorrhage from sources outside

V. Valek $(\bowtie) \cdot$ J. Husty

Department of Radiology, University Hospital Brno

and Medical Faculty of Masaryk University Brno,

Jihlavska 20, 62500 Brno, Czech Republic

e-mail:vlvalek@med.muni.cz

J. Husty

e-mail: jhusty@fnbrno.cz the digestive tract, such as the biliary tract, the pancreatic duct, and arterioenteric fistula, or visceral arteries aneurysms or pseudoaneurysms $[6,7]$.

\section{Definitions}

Transcatheter embolization is defined as the intravascular deposition of particles, liquid, or mechanical agents to produce vessel occlusion. Technical success is typically defined as a cessation of active contrast media extravasation (if present before embolization) from the bleeding site at the end of the procedure. In presence of only indirect signs, it is considered as complete occlusion of pathologically changed arteries or pseudoaneurysms.

Clinical success definition varies greatly between the various reports in the literature. It is usually associated with the resolution of signs and symptoms of bleeding in a defined time period (mostly 30 days). Some studies also include secondary clinical success after repeated embolization in case of recurrent bleeding. Persistence of melena or hematemesis within 12-24 h after the procedure should not be considered a clinical failure if not associated with clear laboratory or clinical signs of blood loss and should not indicate the need for a reintervention.

Acute significant bleeding is generally considered as bleeding requiring transfusion of at least 4 units of blood within $24 \mathrm{~h}$ or causing signs of hemodynamic instability and shock (hypotension systolic BP of $<100$, tachycardia $>100$ ) [8-10].

\section{Pretreatment Imaging}

Radionuclide Tc99 red cell labeling is the most sensitive imaging method, with the ability to detect bleeding from 
$0.1 \mathrm{ml} / \mathrm{min}$ [11]. However, this technique is not able to define precisely the anatomic source of the bleeding. In addition, it can be too time-consuming to use in emergencies. Nowadays, it is mainly used for intermittent bleeding [1].

Conventional digital subtraction angiography (DSA) is able to detect bleeding from amounts of approximately $0.5 \mathrm{ml} / \mathrm{min}[12,13]$. Its sensitivity ranges from 63 to $90 \%$ for upper and 40 to $86 \%$ for lower GI tract [1]. Its sensitivity can be further increased by using provocative angiography with vasodilators (usually Tolazoline $15-30 \mathrm{mg}$ ) [14] or by using carbon dioxide. The classic direct angiographic sign of active GI bleeding is extravasation of contrast material. The indirect signs include mainly presence of pseudoaneurysms, arterial wall irregularities, or vascular tangle with early vein drainage (AVM, angiodysplasia) [6]. The localization of bleeding can be improved by previous placement of metal clips at the source of bleeding during endoscopic examination [15].

MDCT angiography, using the correct protocol, is similarly able to detect bleeding from the amounts of approximately $0.3 \mathrm{ml} / \mathrm{min}$, comparable to conventional angiography $[11,16]$. In addition, compared to conventional angiography, it is able to depict surrounding anatomical structures and to determine not only the place, but also a possible cause of bleeding. MDCT angiography also displays the complete vascular anatomy and may allow better planning of subsequent endovascular intervention [17]. It is generally recommended to include precontrast scans before IV contrast injection to differentiate blood from other high-density material in the bowel. High-speed IV contrast injection is important to opacify adequately the arterial tree and it is generally recommended at $4 \mathrm{ml} / \mathrm{s}$ [18]. Most of the studies also suggest acquisition of delayed (venous) postcontrast scans [1, 18]. Oral contrast should not be administered, because it makes the correct diagnosis difficult. The localization of the bleeding site is usually based on the presence of extravasated IV contrast material within the bowel lumen (Table 1).

Even in hemodynamically unstable patients with acute significant bleeding of obscure localization, MDCT angiography should be considered the imaging method of choice due to its noninvasiveness, speed, and sensitivity. Angiography and embolization generally should be considered in those cases when bleeding is identified on MDCT [1, 11, 20, 21].

Table 1 Usefulness of CT angiography to locate GI bleeding site [19]

\begin{tabular}{ll}
\hline Sensitivity & $89 \%$ \\
Specificity & $85 \%$ \\
\hline
\end{tabular}

\section{Indications for Treatment and Contraindications}

The indication for the procedure is usually based on a multidisciplinary consensus between the gastroenterologist, radiologist, and surgeon. In the event of acute significant gastrointestinal bleeding and after failure of conservative treatment, endoscopy is the method of choice. Endovascular procedures are indicated generally for patients with significant acute gastrointestinal bleeding with endoscopically untreatable or unrevealed source of bleeding or with excessive bleeding that obscures the endoscopic view [6], even in patients with signs of hemodynamic instability.

As indicated above, it is recommended to perform MDCT angiography before the intervention in the case of an unclear source of bleeding and if it is immediately available, it should be considered for hemodynamically unstable patients. In the case of a negative finding on MDCT angiography, the probability of detection of bleeding site in DSA is low $[1,11,20,21]$. Surgical treatment is generally considered in operable patients especially those with a bleeding gastroduodenal peptic ulcer [22] or recurrent bleeding from colonic diverticula [23] and after endoscopy and embolization therapy failure.

Contraindications of embolization in significant GI bleeding are only relative. In addition to general contraindications for iodine-contrast examinations (allergy and renal insufficiency), there are specifically those of coagulopathy and residues of barium sulphate contrast agent after the previous examination (Fig. 1).

\section{Procedure}

The patient preparation before procedure includes initiation of supportive therapy (volumotherapy, etc.) and correction of coagulopathy. Bladder catheter insertion is desirable. During the procedure, blood pressure, heart rate, saturation, and ECG are monitored. In patients with GI bleeding, it is always desirable to have anesthetic and intensive care physician support, particularly in unstable patients.

The most common access used for embolization is the common femoral artery. Use of spasmolytics (i.e., Buscopan) could be helpful to avoid image artefacts. Usually all three unpaired visceral branches of the abdominal aorta are selectively examined with 4-5-F catheter (i.e., Simmons, Cobra, SOS Omni, etc.) to increase diagnostic accuracy before embolization. After verifying the source of bleeding, microcatheters are usually introduced coaxially. The choice of embolic material is individual. The most commonly used embolic materials are 0.018-inch microcoils (also 0.035-, 0.01-inch, and detachable microcoils for precise positioning could be used), PVA microspheres (500-700 $\mu \mathrm{m})$, and gelatin foam. In the case of massive bleeding, the use of 


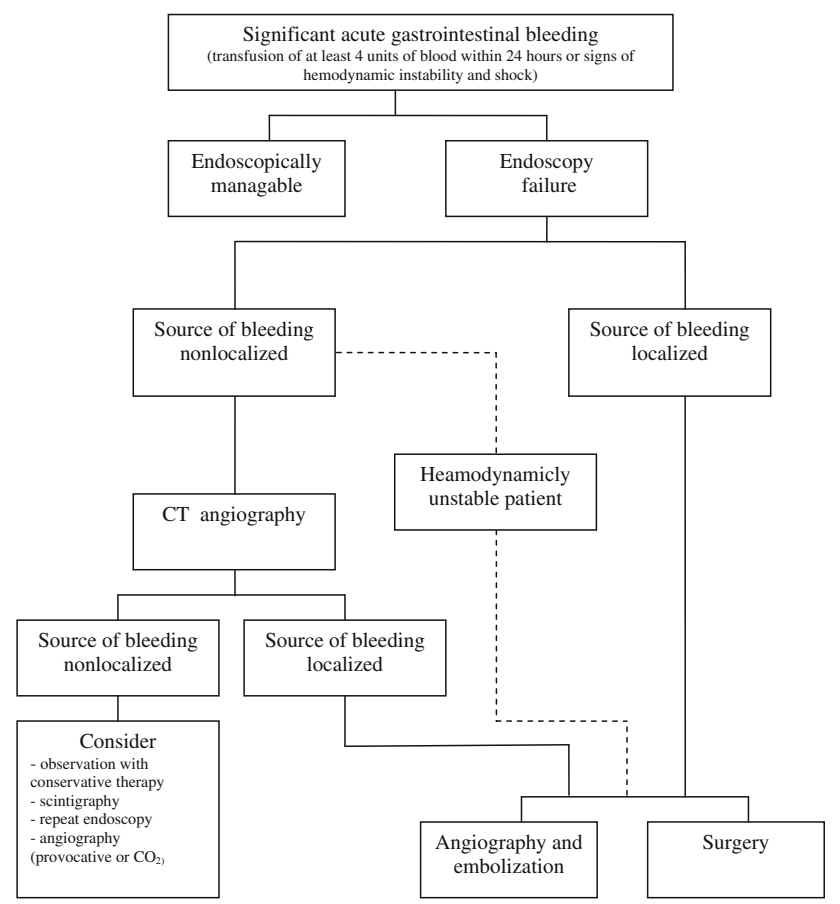

Fig. 1 Algorithm for management of significant acute nonvariceal gastrointestinal bleeding

tissue glue (Histoacryl, etc.) or Onyx may be considered [15] but with increased risk of ischemia and need for further surgical intervention. A combination of embolic materials can be beneficial (microcoils with gelatin foam or microparticles) to reduce the risk of rebleeding [24]. Selective intra-arterial infusion of vasoconstrictor agents is rarely used due to the high frequency of rebleeding $(>50 \%)[8,25$, 26] and occurrence of systemic side effects [6]. It could be considered for diffuse mucosal hemorrhage, diverticular bleeding, postpolypectomy, or lesions inaccessible to a microcatheter. Typically 100 units of vasopressin are mixed in $500 \mathrm{ml}$ of saline and infusion speed is set to between 0.1 and $0.4 \mathrm{U} / \mathrm{min}$ and lasts up to $16 \mathrm{~h}$.

Due to differences in blood supply of the upper and lower GI tract, the technique of embolization also differs. The upper gastrointestinal tract is characterized by a rich network of collateral supply with a lower risk of ischemia. Before the embolization itself, it is necessary to map all the possible sources of collateral supply, especially in the region of gastroduodenal artery and pancreaticoduodenal arcades. Because of the risk of rebleeding via collaterals, it is necessary to perform embolization proximally and distally from the site of bleeding (so-called sandwich method) [8].

In the lower gastrointestinal tract, in particular in the colon, there is a higher portion of terminal branches. Therefore, the ischemia risk is higher and embolization should be as selective as possible [27]. Due to the poor submucosal collateral circulation, extensive embolization from the periphery to proximal vessels may interrupt the blood supply for a longer part of the intestine and therefore could cause bowel ischemia [6]. Use of particles of $700 \mu \mathrm{m}$ or larger is advisable in order not to compromise the submucosal circulation and lower the risk of ischemia.

\section{Outcome}

The presence of uncorrectable coagulopathy is the most significant negative predictive factor for recurrent bleeding and mortality $[9,15]$. Other negative predictive factors include older age, cirrhosis, oncologic diseases, multiple organ failure, and current corticosteroid treatment [7, 56]. Generally, the morbidity and mortality associated with endovascular intervention is lower or comparable than for surgical procedure [28, 42, 57-59].

In view of the lower morbidity and mortality compared with open surgery is endovascular therapy, which is now considered the treatment of choice for GI bleeding following failed medical and endoscopic therapy (Table 2).

\section{Complications}

In addition to the standard rate of nonspecific complications associated with other angiographic procedures (such as reactions to the contrast agent, renal failure, local complications in the groin, dissection, vasospasm), the most common and specific complication of GI embolization is ischemia. In the upper GI tract, the risk of ischemia is low due to the rich collateral supply. Duodenal stenosis as a result of duodenal ischemia following embolization is low and reported to be less than $7 \%$ [60]. Patients are at increased risk of ischemia if they have a previous history of surgery or radiotherapy [9] and after embolization with glue or microparticles [6, 60].

Other rare, specific complications include unintentional main hepatic artery embolization with the risk of liver failure [15]. Overall average complication rate is approximately $9 \%$ [28].

Similarly, in the lower GI tract, the most common specific complication is intestinal ischemia. The mild form

Table 2 Outcome

\begin{tabular}{ll}
\hline Upper GI bleeding [15, 28-41] & \\
Technical success & $93 \%$ \\
Clinical success & $67 \%$ \\
Rebleeding rate & $33 \%$ \\
Lower GI bleeding [5, 42-55] & \\
Technical success & $95 \%$ \\
Clinical success & $76 \%$ \\
Rebleeding rate & $24 \%$ \\
\hline
\end{tabular}


(transient abdominal pain and asymptomatic stenosis) occurs in $10 \%$. Severe ischemic complications requiring surgical treatment (symptomatic ischemic stenosis, intestinal infarction) occur in $2 \%$ [5].

Conflict of interest The authors, Jakub Husty and Vlastimil Valek, declare that they have no conflict of interest.

\section{References}

1. Laing CJ, Tobias T, Rosenblum DI, Banker WL, Tseng L, Tamarkin SW (2007) Acute gastrointestinal bleeding: emerging role of multidetector CT angiography and review of current imaging techniques [review]. Radiographics 27(4):1055-1070

2. Hernández-Díaz S, Rodríguez LA (2002) Incidence of serious upper gastrointestinal bleeding/perforation in the general population: review of epidemiologic studies [review]. J Clin Epidemiol 55(2):157-163

3. Albeldawi M, Qadeer MA, Vargo JJ (2010) Managing acute upper GI bleeding, preventing recurrences [review]. Cleve Clin J Med 77(2):131-142

4. Lee EW, Laberge JM (2004) Differential diagnosis of gastrointestinal bleeding [review]. Tech Vasc Interv Radiol 7(3):112-122

5. Weldon DT, Burke SJ, Sun S, Mimura H, Golzarian J (2008) Interventional management of lower gastrointestinal bleeding [review]. Eur Radiol 18(5):857-867 Epub 2008 Jan 8

6. Walker TG (2009) Acute gastrointestinal hemorrhage [review]. Tech Vasc Interv Radiol 12(2):80-91

7. Leonhardt H, Mellander S, Snygg J, Lönn L (2008) Endovascular management of acute bleeding arterioenteric fistulas. Cardiovasc Intervent Radiol 31(3):542-549

8. Burke SJ, Golzarian J, Weldon D, Sun S (2007) Nonvariceal upper gastrointestinal bleeding [review]. Eur Radiol 17(7): $1714-1726$

9. Loffroy R, Guiu B (2009) Role of transcatheter arterial embolization for massive bleeding from gastroduodenal ulcers. World $\mathbf{J}$ Gastroenterol 15(47):5889-5897

10. Nicholson AA, Ettles DF, Hartley JE et al (1998) Transcatheter coil embolotherapy: a safe and effective option for major colonic haemorrhage. Gut 43:79-84

11. Stunell H, Buckley O, Lyburn ID, McGann G, Farrell M, Torreggiani WC (2008) The role of computerized tomography in the evaluation of gastrointestinal bleeding following negative or failed endoscopy: a review of current status [review]. J Postgrad Med 54(2):126-134

12. Baum ST (2006) Arteriographic diagnosis and treatment of gastrointestinal bleeding. In: Baum ST, Pentecost MJ (eds) Abram's angiography interventional radiology, 2nd edn. Lippincott Williams \& Wilkins, Philadelphia, p 488

13. Joo I, Kim HC, Chung JW, Jae HJ, Park JH (2009) Risk factors for rebleeding after angiographically negative acute gastrointestinal bleeding. World J Gastroenterol 15(32):4023-4027

14. Johnston C, Tuite D, Pritchard R, Reynolds J, McEniff N, Ryan JM (2007) Use of provocative angiography to localize site in recurrent gastrointestinal bleeding. Cardiovasc Intervent Radiol 30(5): 1042-1046

15. Aina R, Oliva VL, Therasse E, Perreault P, Bui BT, Dufresne MP, Soulez G (2001) Arterial embolotherapy for upper gastrointestinal hemorrhage: outcome assessment. J Vasc Interv Radiol 12(2): 195-200

16. Ernst O, Bulois P, Saint-Drenant S, Leroy C, Paris JC, Sergent (2003) Helical CT in acute lower gastrointestinal bleeding. Eur Radiol 13(1):114-117
17. Foley PT, Ganeshan A, Anthony S, Uberoi R (2010) Multidetector CT angiography for lower GI bleeding; can it select for endovascular therapy. J Med Imaging Radia Oncol 54:9-16

18. Anthony S, Milburn S, Uberoi R (2007) Multi-detector CT: review of its use in acute GI haemorrhage. Clin Radiol 62(10): 938-949

19. Wu LM, Xu JR, Yin Y, Qu XH (2010) Usefulness of CT angiography in diagnosing acute gastrointestinal bleeding: a metaanalysis. World J Gastroenterol 16(31):3957-3963

20. Jaeckle T, Stuber G, Hoffmann MH, Jeltsch M, Schmitz BL, Aschoff AJ (2008) Detection and localization of acute upper and lower gastrointestinal (GI) bleeding with arterial phase multidetector row helical CT. Eur Radiol 18(7):1406-1413 Epub 2008 Mar 20

21. Yoon W, Jeong YY, Shin SS, Lim HS, Song SG, Jang NG, Kim JK, Kang HK (2006) Acute massive gastrointestinal bleeding: detection and localization with arterial phase multi-detector row helical CT. Radiology 239(1):160-167

22. Defreyne L, De Schrijver I, Decruyenaere J, Van Maele G, Ceelen W, De Looze D, Vanlangenhove P (2008) Therapeutic decision-making in endoscopically unmanageable nonvariceal upper gastrointestinal hemorrhage. Cardiovasc Intervent Radiol 31(5):897-905

23. Lee J, Costantini TW, Coimbra R (2009) Acute lower GI bleeding for the acute care surgeon: current diagnosis and management [review]. Scand J Surg 98(3):135-142

24. Loffroy R, Guiu B, Mezzetta L, Minello A, Michiels C, Jouve JL, Cheynel N, Rat P, Cercueil JP, Krausé D (2009) Short- and longterm results of transcatheter embolization for massive arterial hemorrhage from gastroduodenal ulcers not controlled by endoscopic hemostasis. Can J Gastroenterol 23(2):115-120

25. Fallah MA, Prakash C, Edmundowicz S (2000) Acute gastrointestinal bleeding [review]. Med Clin North Am 84(5):1183-1208

26. Gomes AS, Lois JF, McCoy RD (1986) Angiographic treatment of gastrointestinal hemorrhage: comparison of vasopressin infusion and embolization. AJR Am J Roentgenol 146(5):1031-1037

27. Funaki B (2004) Superselective embolization of lower gastrointestinal hemorrhage: a new paradigm [review]. Abdom Imaging 29(4):434-438

28. Loffroy R, Rao P, Ota S, De Lin M, Kwak BK, Geschwind JF (2010) Embolization of acute nonvariceal upper gastrointestinal hemorrhage resistant to endoscopic treatment: results and predictors of recurrent bleeding. Cardiovasc Intervent Radiol 33(6): $1088-1100$

29. Encarnacion CE, Kadir S, Beam CA, Payne CS (1992) Gastrointestinal bleeding: treatment with gastrointestinal arterial embolization. Radiology 183(2):505-508

30. Toyoda H, Nakano S, Kumada T, Takeda I, Sugiyama K, Osada T, Kiriyama S (1996) Estimation of usefulness of $N$-butyl-2-cyanoacrylate-lipiodol mixture in transcatheter arterial embolization for urgent control of life-threatening massive bleeding from gastric or duodenal ulcer. J Gastroenterol Hepatol 11(3): 252-258

31. Walsh RM, Anain P, Geisinger M, Vogt D, Mayes J, GrundfestBroniatowski S, Henderson JM (1999) Role of angiography and embolization for massive gastroduodenal hemorrhage. J Gastrointest Surg 3(1):61-65 discussion 66

32. Schenker MP, Duszak R Jr, Soulen MC, Smith KP, Baum RA, Cope C, Freiman DB, Roberts DA, Shlansky-Goldberg RD (2001) Upper gastrointestinal hemorrhage and transcatheter embolotherapy: clinical and technical factors impacting success and survival. J Vasc Interv Radiol 12(11):1263-1271

33. Defreyne L, Vanlangenhove P, De Vos M, Pattyn P, Van Maele G, Decruyenaere J, Troisi R, Kunnen M (2001) Embolization as a first approach with endoscopically unmanageable acute nonvariceal gastrointestinal hemorrhage. Radiology 218(3):739-748 
34. De Wispelaere JF, De Ronde T, Trigaux JP, de Cannière L, De Geeter T (2002) Duodenal ulcer hemorrhage treated by embolization: results in 28 patients. Acta Gastroenterol Belg 65(1):6-11

35. Ripoll C, Bañares R, Beceiro I, Menchén P, Catalina MV, Echenagusia A, Turegano F (2004) Comparison of transcatheter arterial embolization and surgery for treatment of bleeding peptic ulcer after endoscopic treatment failure. J Vasc Interv Radiol 15(5): $447-450$

36. Holme JB, Nielsen DT, Funch-Jensen P, Mortensen FV (2006) Transcatheter arterial embolization in patients with bleeding duodenal ulcer: an alternative to surgery. Acta Radiol 47(3):244-247

37. Ichiro I, Shushi H, Akihiko I, Yasuhiko I, Yasuyuki Y (2011) Empiric transcatheter arterial embolization for massive bleeding from duodenal ulcers: efficacy and complications. J Vasc Interv Radiol 22(7):911-916

38. Larssen L, Moger T, Bjørnbeth BA, Lygren I, Kløw NE (2008) Transcatheter arterial embolization in the management of bleeding duodenal ulcers: a 5.5-year retrospective study of treatment and outcome. Scand J Gastroenterol 43(2):217-222

39. Poultsides GA, Kim CJ, Orlando R 3rd, Peros G, Hallisey MJ, Vignati PV (2008) Angiographic embolization for gastroduodenal hemorrhage: safety, efficacy, and predictors of outcome. Arch Surg 143(5):457-461

40. Loffroy R, Guiu B, D’Athis P, Mezzetta L, Gagnaire A, Jouve JL, Ortega-Deballon P, Cheynel N, Cercueil JP, Krausé D (2009) Arterial embolotherapy for endoscopically unmanageable acute gastroduodenal hemorrhage: predictors of early rebleeding. Clin Gastroenterol Hepatol 7(5):515-523

41. Padia SA, Geisinger MA, Newman JS, Pierce G, Obuchowski NA, Sands MJ (2009) Effectiveness of coil embolization in angiographically detectable versus non-detectable sources of upper gastrointestinal hemorrhage. J Vasc Interv Radiol 20(4):461-466

42. Funaki B (2004) Microcatheter embolization of lower gastrointestinal hemorrhage: an old idea whose time has come [review]. Cardiovasc Intervent Radiol 27(6):591-599

43. Tan KK, Wong D, Sim R (2008) Superselective embolization for lower gastrointestinal hemorrhage: an institutional review over 7 years. World J Surg 32(12):2707-2715

44. Guy GE, Shetty PC, Sharma RP et al (1992) Acute lower gastrointestinal hemorrhage: treatment by superselective embolization with polyvinyl alcohol particles. Am J Roentgenol 159:521-526

45. Gordon RL, Ahl KL, Kerlan RK et al (1997) Selective arterial embolization for the control of lower gastrointestinal bleeding. Am J Surg 174:24-28

46. Peck DJ, McLoughlin RF, Hughson MN, Rankin RN (1998) Percutaneous embolotherapy of lower gastrointestinal hemorrhage. J Vasc Interv Radiol 9:747-751
47. Ledermann HP, Schoch E, Jost R et al (1998) Superselective coil embolization in acute gastrointestinal hemorrhage: personal experience in 10 patients and review of the literature. J Vasc Interv Radiol 9:753-760

48. Nicholson AA, Ettles DF, Hartley JE et al (1998) Transcatheter coil embolotherapy: a safe and effective option for major colonic haemorrhage. Gut 43:79-84

49. Evangelista PT, Hallisey MJ (2000) Transcatheter embolization for acute lower gastrointestinal hemorrhage. J Vasc Interv Radiol 11:601-606

50. Luchtefeld MA, Senagore AJ, Szomstein M et al (2000) Evaluation of transarterial embolization for lower gastrointestinal bleeding. Dis Colon Rectum 43:532-534

51. Kramer SC, Gorich J, Rilinger N et al (2000) Embolization for gastrointestinal hemorrhages. Eur Radiol 10:802-805

52. Funaki B, Kostelic JK, Lorenz J et al (2001) Superselective microcoil embolization of colonic hemorrhage. AJR 177:829-836

53. Bandi R, Shetty PC, Sharma RP et al (2001) Superselective arterial embolization for the treatment of lower gastrointestinal hemorrhage. J Vasc Interv Radiol 12:1399-1405

54. Patel TH, Cordts PR, Abcarian P, Sawyer MA (2001) Will transcatheter embolotherapy replace surgery in the treatment of gastrointestinal bleeding? Curr Surg 58:323-327

55. Defreyne L, Vanlangenhove P, De Vos M et al (2001) Embolization as a first approach with endoscopically unmanageable acute nonvariceal gastrointestinal hemorrhage. Radiology 218: 739-748

56. Schenker MP, Duszak R Jr, Soulen MC, Smith KP, Baum RA, Cope C, Freiman DB, Roberts DA, Shlansky-Goldberg RD (2001) Upper gastrointestinal hemorrhage and transcatheter embolotherapy: clinical and technical factors impacting success and survival. J Vasc Interv Radiol 12(11):1263-1271

57. Eriksson LG, Ljungdahl M, Sundbom M, Nyman R (2008) Transcatheter arterial embolization versus surgery in the treatment of upper gastrointestinal bleeding after therapeutic endoscopy failure. J Vasc Interv Radiol 19(10):1413-1418

58. Langner I, Langner S, Partecke LI, Glitsch A, Kraft M, Bernstorff W, Hosten N (2008) Acute upper gastrointestinal hemorrhage: is a radiological interventional approach an alternative to emergency surgery? Emerg Radiol 15(6):413-419

59. Chevallier P, Novellas S, Vanbiervliet G, Staccini P, Le Conte L, Hébuterne X, Bruneton JN (2007) Transcatheter embolization for endoscopically unmanageable acute nonvariceal upper gastrointestinal hemorrhage. J Radiol 88(2):251-258

60. Lang EK (1992) Transcatheter embolization in management of hemorrhage from duodenal ulcer: long-term results and complications. Radiology 182(3):703-707 